\title{
Diagnosis: Genetic Testing Cannot Stand Alone
}

\author{
Estela Morales-Peralta MD PhD
}

Genetic testing uses advanced laboratory techniques to identify protein alterations, certain metabolites, chromosomes, or nucleic acids by which a genotype is determined or inferred. These tests provide insights into the molecular basis and physiopathology of genetic diseases, information which is critical for prevention, treatment and genetic counseling.

Initiated in 1982, Cuba's National Program for Diagnosis, Management and Prevention of Birth Defects and Hereditary Diseases ensures availability of genetic tests to all Cubans who need them, free of charge, assisting physician-patient decisions. The tests may be used to confirm diagnoses, point to hereditary diseases and potential congenital problems during pregnancy or in pre-symptomatic stages, and diagnose carriers of recessive diseases.

However, a positive test does not necessarily indicate presence of a particular disease: for diagnostic certainty, these analyses must be included in the battery of laboratory tests that complement a patient's extensive exam and thorough interview included in the time-honored clinical method.

Indeed, genetic heterogeneity (the fact that more than one mutation can cause a particular disease) may lead to diagnostic errors if genetic test results are considered in isolation. In cases of hereditary diseases with genetic heterogeneity, the best course is an approach that combines findings from clinical symptoms and these complementary tests, leading to greater diagnostic accuracy than provided only by identification of nucleic acid alterations through molecular studies.

Moreover, not all people with a particular genetic mutation develop the disease in question. For instance, in hereditary colorectal cancer syndrome, one quarter will not develop the disease.[1] In this case, the mutation is said to have reduced penetrance. Reduced penetrance in disease-associated mutations shows that genetic testing's specificity is not always absolute, since healthy people might be misdiagnosed solely on the basis of a certain genetic alteration

Finally, a single genetic change may produce more than one disease. The ale3243gly point mutation in mitochondrial DNA is associated with two syndromes: maternally inherited diabetes and deafness (MIDD) and mitochondrial encephalomyopathy with lactic acidosis and stroke-like episodes (MELAS). These are distinct illnesses requiring different interventions. Other examples are the cys342arg mutation in the fibroblast growth factor receptor 2 gene (FGFR2), which can trigger three separate conditions (Pfeiffer, Crouzon, and Jackson-Weiss syndromes); and the deltamtDNA(4977) mutation, which produces Kearns-Sayre and Pearson syndromes.[2]

Similarly, cytosine-adenine-guanine (CAG) expansion mutations in the ataxin-2 gene (ATXN2) cause spinocerebellar ataxia type 2; identification of this genetic change is useful for presymptomatic diagnosis of the disease. However, expansion length overlapping has been found in spinocerebellar ataxia type 2, Parkinson's dis-

ease and amyotrophic lateral sclerosis. A number of intermediatelength CAG expansions in the ataxin-2 gene exist, but even when they are identified, it is not possible to determine during the presymptomatic stage which of these diseases - if any-will develop later.

The above are just a few examples demonstrating that diagnosis of genetic diseases cannot rely solely on genetic testing. These support diagnosis, but cannot constitute its sole basis: they must be complemented by traditional (and sometimes more sensitive and specific) clinical and laboratory criteria.

...laboratory tests,
including genetic ones,
should be considered
part and parcel of the
clinical method

In fact, the selection of laboratory tests, including genetic ones, should be considered part and parcel of the clinical method-the main guarantee of quality care in Cuba's public health services. The clinical method applies the scientific method to individual patient care. It is based on a logical step-by-step sequence derived from a comprehensive patient interview and physical exam. Based on these preliminary findings, the physician formulates diagnostic hypotheses-confirmed by laboratory tests when warranted, and genetic testing when appropriate.[2] And this is as it should be: technology has now become such an integral part of the clinical method that rendering a diagnosis without some confirmatory study is, in many cases, inconceivable.

Thus, mine is not an anti-technology argument, but holds instead, that testing and technology should not be relied upon in isolation for diagnosis. While the trend is to look to technology for solutions to everything-including in medicine-diagnosis remains a human activity and ultimately the responsibility of well-trained physicians who constantly not only update their scientific knowledge but also hone their clinical skills. Wh

1. Moreno MA. El diagnóstico médico. Principios seculares y problemas actuales. Havana: Editorial Científico Técnica; 2001. 178 p. Spanish.

2. Online Mendelian Inheritance in Man [Internet]. Baltimore: McKusick-Nathans Institute of Genetic Medicine, Johns Hopkins University; 2014 Jan 23 [cited 2014 April 4]. Available at: http://omim.org

Submitted: June 25, 2013

Approved for publication: July 30, 2014

Disclosures: None

Correspondence: fornaris@infomed.sld.cu 